\title{
Comparison of Caudal Bupivacaine, Bupivacaine with Fentanyl and Bupivacaine with Tramadol Administration for Post Operative Analgesia in Children
}

\author{
Pavithra ${ }^{1 *}$, Monal Ramani ${ }^{2}$, Pratham Bysani ${ }^{3}$ and Deepti Srinivas ${ }^{4}$ \\ ${ }^{1}$ Department of Anesthesiology, MS Ramaiah Medical College, India \\ ${ }^{2}$ Department of Anesthesiology, BJ Medical College, India \\ ${ }^{3}$ Bangalore Medical College and Research Institute, India \\ ${ }^{4}$ National Institute of Mental Health and Neurosciences, India
}

Submission: March 07, 2017; Published: March 21, 2018

*Corresponding author: Pavithra V, Department of Anesthesiology, MS Ramaiah Medical College, Ahmedabad, India, Email: drpavithrav@gmail.com

Abstract

Objective: To compare the effectiveness of caudal bupivacaine, bupivacaine plus fentanyl and bupivacaine plus tramadol for post operative analgesia in children.

Materials and methods: The study was conducted on 75 children of ASA I and II physical status aged 1 to 12 years undergoing elective infraumbilical surgeries. Patients were divided into 3 groups and the following were given in the caudal epidural space after the induction of anesthesia:

a) Group I: $0.125 \%$ Inj. Bupivacaine $1 \mathrm{ml} / \mathrm{kg}$

b) Group II: 0.125 Inj. Bupivacaine $1 \mathrm{ml} / \mathrm{kg}$ plus Inj. Fentanyl $1 \mathrm{mcg} / \mathrm{kg}$

c) Group III: $0.125 \%$ Inj. Bupivacaine $1 \mathrm{ml} / \mathrm{kg}$ plus Inj. Tramadol 2mg/kg

Results: Group III had a lower pain score, prolonged mean duration of analgesia, less requirement for rescue analgesics compared to the other two groups.

Conclusion: Addition of Tramadol to Bupivacaine provides prolonged and good quality post operative analgesia in comparison with Bupivacaine alone or with Fentanyl in Caudal Block in the post operative period.

Keywords: Caudal; Bupivacaine; Fentanyl; Tramadol; Pediatric; Analgesia

\section{Introduction}

Postoperative analgesia through the caudal epidural route with bupivacaine in children is firmly established in infra umbilical surgery $[1,2]$. The mean duration of surgical analgesia provided by bupivacaine is limited [3] Different drugs such as tramadol, fentanyl, clonidine, and midazolam with bupivacaine prolong the postoperative analgesia. Tramadol is a centrally acting analgesic effect via opioid receptors [4]. The main site of action of epidurally administered fentanyl is the substantia gelatinosa on the dorsal horn of spinal cord [5]. We evaluated the duration of postoperative analgesia, intraoperative hemodynamic changes, sedation score and any side effect while using caudal block with bupivacaine, tramadol and fentanyl in pediatric patients undergoing infraumbilical surgeries.

\section{Aims and Objectives}

a. To compare the duration of post operative analgesia.

b. To evaluate the effect on haemodymamic changes in the intra operative and post operative period.

c. To study the perioperative complications.

d. To compare the total number of rescue analgesics used during the 24 hour post operative period in each group.

\section{Material and Methods}

After obtaining Institutional Ethical Committee approval, written and informed consent were obtained from parents. This is a prospective, randomized, controlled, single-blind study. We 
recruited 75 children of either sex with American Society of Anesthesiologist (ASA) physical status I and II, aged 1-12 years, weighing 5-30 kg who was scheduled for elective infra umblical surgeries of similar duration under general anesthesia. Patients are having a local infection at the caudal site, neurological disorder, the history of allergic reaction to local anesthetics, sacral/vertebral abnormalities, and bleeding diathesis were excluded from the study. An intravenous access was secured, and glycopyrrolate injection $(0.004 \mathrm{mg} / \mathrm{kg})$ and ondansetron injection $(0.15 \mathrm{mg} / \mathrm{kg})$ were administered. Standard monitoring including an electrocardiogram (ECG), noninvasive blood pressure (NIBP) measurement, pulse oximetry, capnography, and temperature were applied. All patients were induced with either inhalational agent sevoflurane (1-6\%) with $50 \%$ nitrous oxide in oxygen. In the left lateral position, caudal block was performed using 22-gauge epidural needle under complete aseptic precautions. After confirmation and negative aspiration for blood and cerebrospinal fluid, the drugs (bupivacaine/tramadol/fentanyl) were introduced into the caudal space slowly with continuous ECG monitoring (Figure 1).

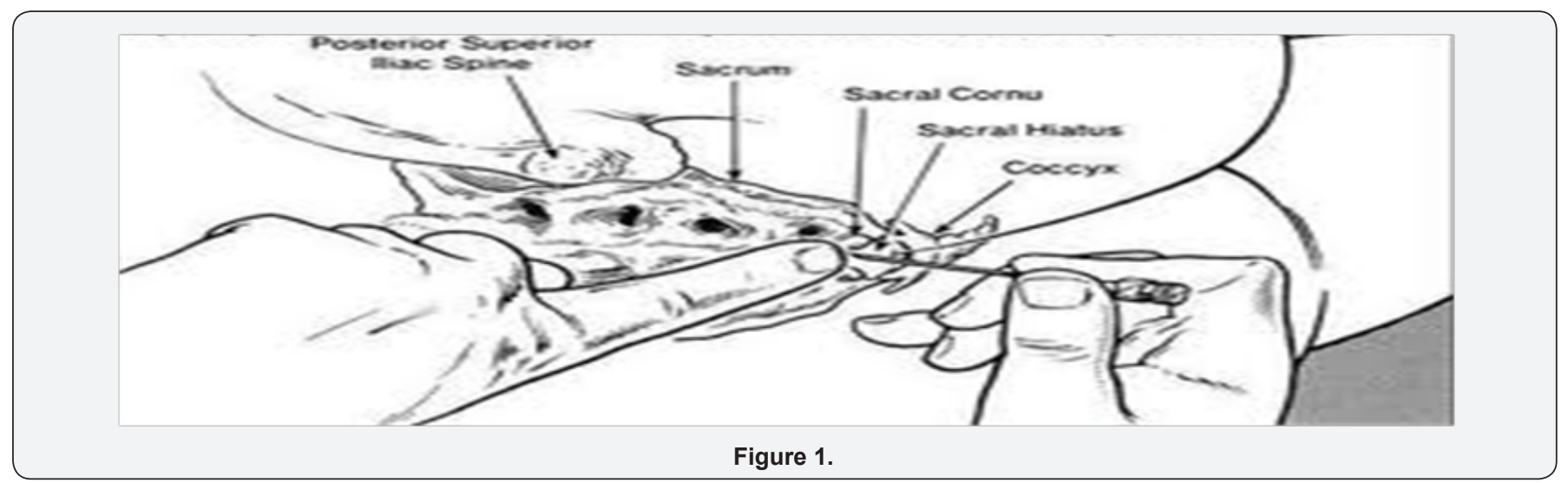

Patients were randomly allocated into 3 groups and the following drug was administered caudally:

a. Group 1: Inj. Bupivacaine $0.125 \% 1 \mathrm{ml} / \mathrm{kg}$

b. Group 2: Inj. Bupivacaine 0.125\% 1ml/kg + Inj .Fentanyl $1 \mathrm{mcg} / \mathrm{kg}$

c. Group 3: Inj. Bupivacaine $0.125 \% 1 \mathrm{ml} / \mathrm{kg}+$ Inj. Tramadol $2 \mathrm{mg} / \mathrm{kg}$

d. HR, BP and SpO2 were recorded before induction, 5 minutes after caudal analgesia and every 15 minutes during the surgery.

e. At the completion of surgery, patients were extubated and were observed for 2 hours in the recovery room for vitals.

The following parameters were noted for:

a. Post operative pain assessed at 30mins, 2 hours, 4, 8, 12, 24 hours after recovery from anesthesia using Modified objective pain score(MOPS).

b. Time at which post operative rescue analgesia was first received and the number were noted

c. Sedation score at $1 \mathrm{hr}$ and 4 hours after recovery from analgesia using objective score based on the eye opening.

d. Incidence of adverse effects was evaluated.

The anesthesiologist performing the caudal block was blinded to the identity of the drug used. The patients were repositioned supine. This was followed by insertion of Igel. Intraoperatively, no analgesic was supplemented. Anesthesia was maintained with assisted ventilation using sevoflurane initially with $2 \%$ and then after decreasing up to $0.6 \%$ with hemodynamic stability or controlled ventilation using injection atracurium $(0.5 \mathrm{mg} / \mathrm{kg})$ with $50 \%$ nitrous oxide in oxygen and sevoflurane decreases up to $0.6 \%$ with hemodynamic stability. Glucose/saline solution was infused as per requirement, and perioperative blood loss was replaced as per requirement.

During surgery, adequate analgesia was assessed by hemodynamic stability, as indicated an increase in heart rate and systolic blood pressure of no more than $15 \%$ compared with baseline values obtained just before the surgical incision with decreased requirement of sevoflurane concentration, at approximately $0.6 \%$. An increase in heart rate and systolic blood pressure within 20 min of skin incision indicated failure of caudal anesthesia. At the end of surgery, the residual neuromuscular block was antagonized with glycopyrrolate injection $0.008 \mathrm{mg} / \mathrm{kg}$ and neostigmine injection $0.05 \mathrm{mg} / \mathrm{kg}$ intravenously. Intraoperatively required concentration of sevoflurane was recorded at every 15 min. Heart rate, $\mathrm{NIBP}, \mathrm{SpO}_{2}, \mathrm{EtCO}_{2}$, and temperature were recorded at every $15 \mathrm{~min}$ interval till the end of surgery and every hourly interval postoperatively till rescue analgesic was given.

Duration of surgery, duration of anesthesia, and perioperative complications such as brady/tachycardia, hypo/hypertension, vomiting, and urinary retention were recorded. In the recovery room, hemodynamic parameters, sedation, and pain score were recorded at hourly interval till rescue analgesic was given. Postoperative sedation was assessed by using four point sedation score ( 0 - spontaneous eye opening, 1 - eye open on speech, 2 - eye open on shake, 3 - unarousable), and pain was evaluated by using 
FLACC ( $\mathrm{F}=$ Face, $\mathrm{L}=$ Leg, A = Activity, C = Cry, C = Consolability), score (maximum score of 10 ) at $1 \mathrm{~h}$ interval for first $3 \mathrm{~h}$ and thereafter every $2 \mathrm{~h}$ interval till score $>4$, and rescue analgesic was given. The use of FLACC is a valid and reliable tool for assessing procedural pain in children aged 5-16 years [6-8]. The Collected data were presented as a mean \pm standard deviation, numbers, and percentages as appropriate. A value of $\mathrm{P}<0.05$ was considered as a statistically significant difference with ANOVA being done for statistical analysis among the 3 groups, a student's t test for analgesics between any 2 out of 3 groups for various parameters a

\section{Observation \& Results}

a. Intra OP Pulse Rate: Remained stable without any significant fluctuation in all three groups

b. Post Operative MOP (Modified Objective Pain Score) SCORE: Significant difference was seen among Group 3 and the other groups

c. Group 3 shows a significant difference for First Rescue Analgesic \& Mean Duration of Analgesia with the least no. of rescue analgesics than the other groups

d. Onset of Pain is seen in between 8-12 hrs in Group 3 as against 4-8 hrs in the other groups

e. Mean Sedation Score is on higher side at 4-8 hrs postoperatively than other groups

f. Among post op complications, vomiting was $32 \%$ in Group 3, 28\% in Group 2 \& 0\% in Group 1 (Figure 1-7, Table 1).

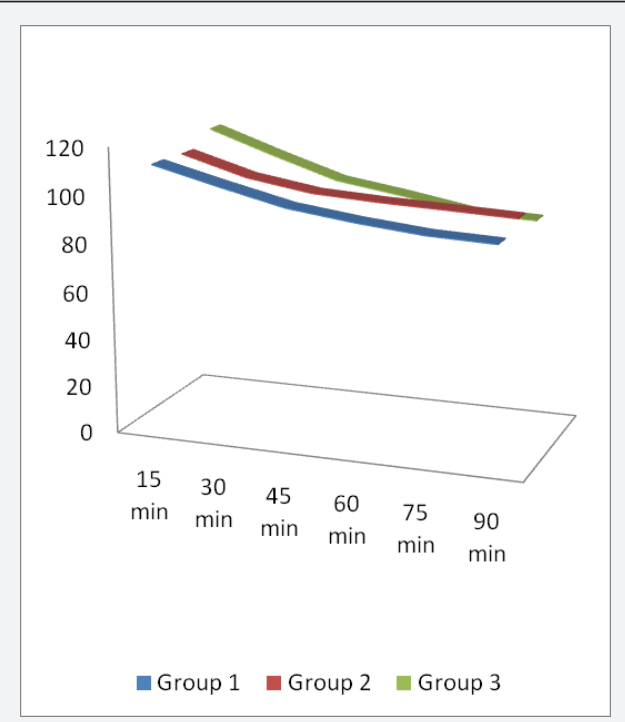

Figure 2: Intra OP Pulse Rate: Remained stable without any significant Fluctuation in all three groups.

Table 1.

\begin{tabular}{|c|c|c|c|}
\hline & Group 1 & Group 2 & Group 3 \\
\hline Duration of Analgesia & Less & Less & Maximum \\
\hline $\begin{array}{c}\text { Mean no. of Rescue } \\
\text { Analgesics }\end{array}$ & More & More & Less \\
\hline
\end{tabular}

\begin{tabular}{|c|c|c|c|}
\hline Hemodynamics & Stable & Stable & Stable \\
\hline Nausea \& Vomiting & None & Mild & Mild \\
\hline
\end{tabular}
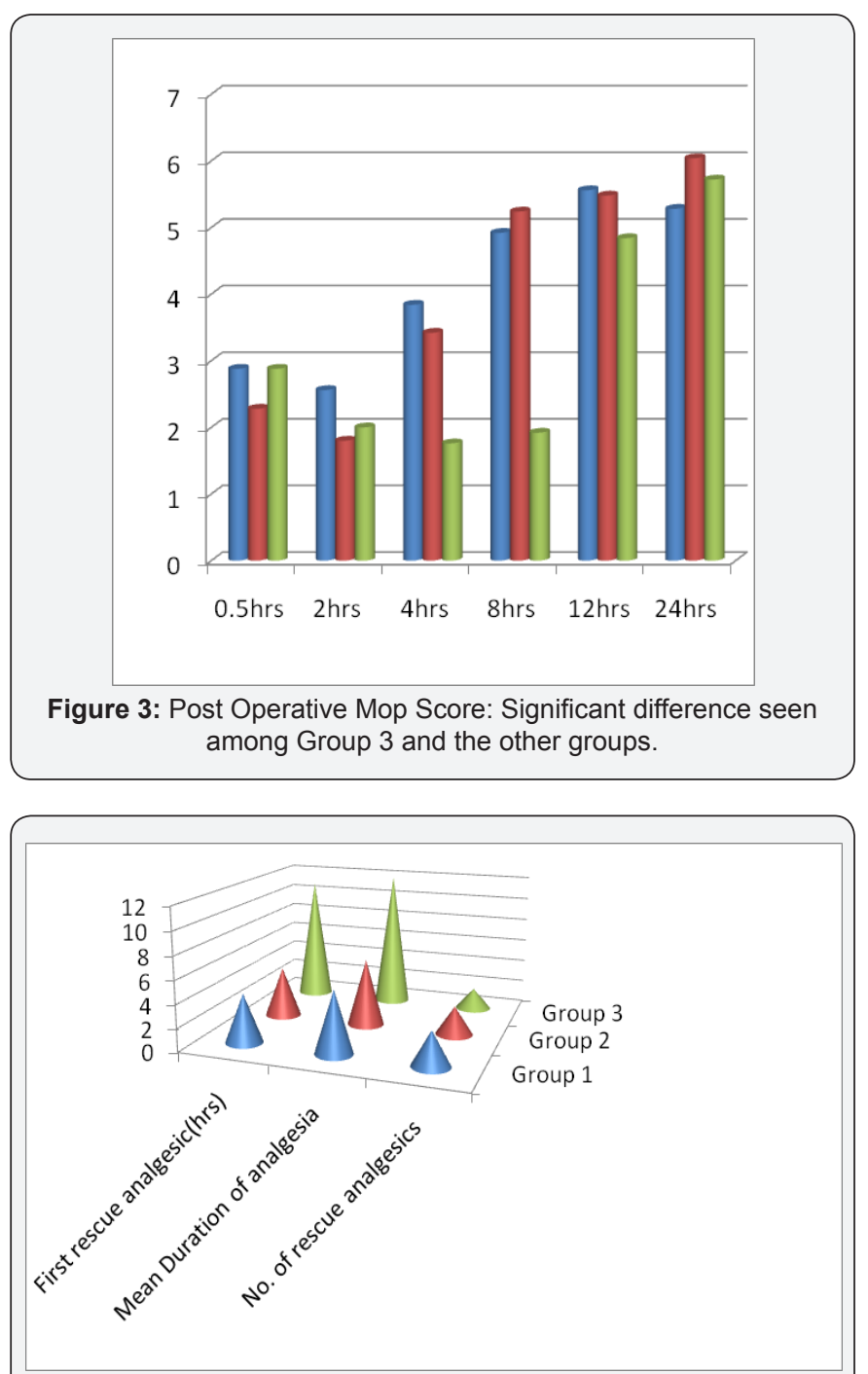

Figure 4: Group 3 shows a significant difference for first rescue analgesic \& mean duration of analgesia with the least no. of rescue analgesics than the other groups.

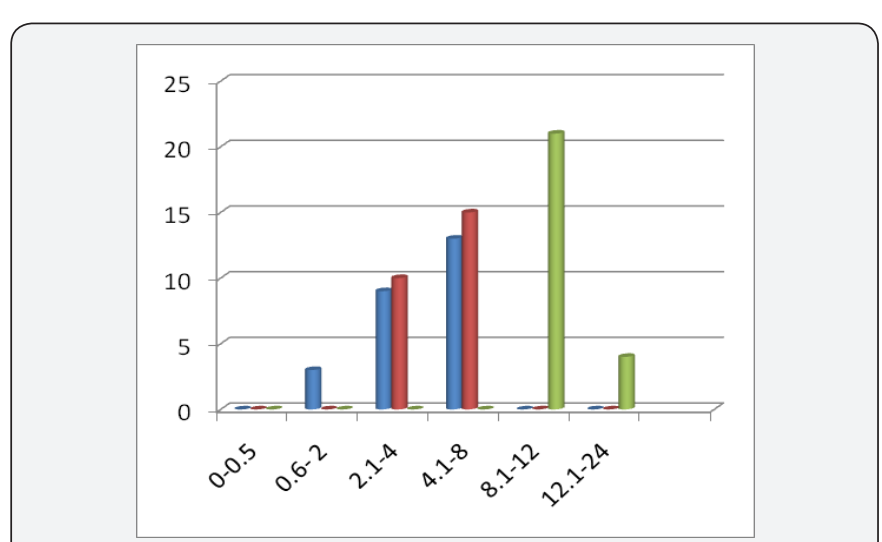

Figure 5: Onset of Pain is seen in between 8-12 hrs in Group 3 as against $4-8 \mathrm{hrs}$ in the other groups. 


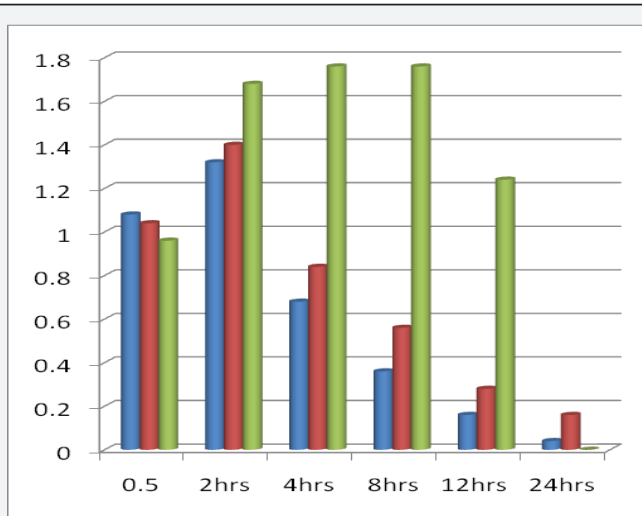

Figure 6: Mean Sedation Score is on higher side at 4-8 hrs postoperatively than other groups.

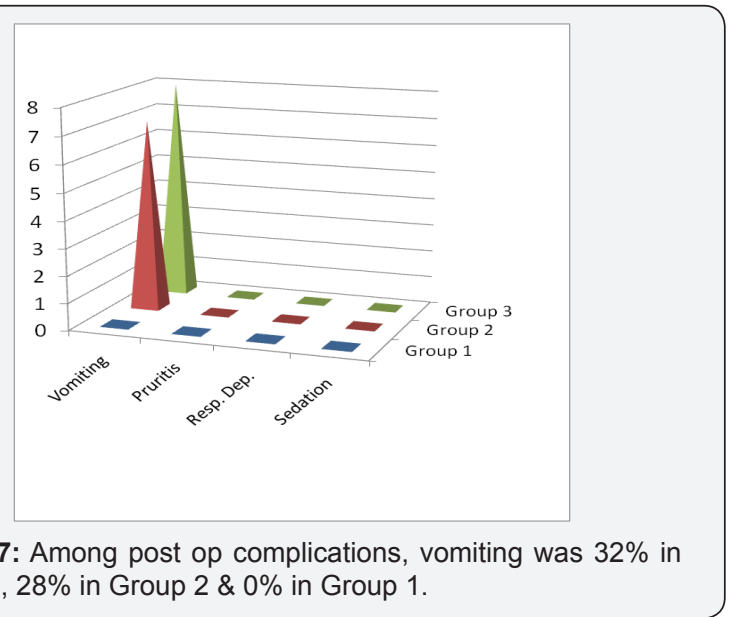

Figure 7: Among post op complications, vomiting was $32 \%$ in Group 3, 28\% in Group 2 \& 0\% in Group 1 .

\section{Discussion}

Pain after surgery is inevitable, and the relief of postoperative pain has been consistently and systematically inadequate. A caudal block is one of the common regional anesthetic techniques used in pediatric age group undergoing infraumbilical surgery [6]. It is generally considered a simple, safe procedure with more reliability, and predictability of the cephalic spread of local anesthetic solution in children than in adults. It produces minimal hemodynamic changes and provides some pain-free period intraoperatively and postoperatively in infraumbilical surgeries in children $[1,2,9]$. Analgesic effect of caudal bupivacaine terminates early, and supplementary analgesics are required in the postoperative period. Various adjuvant drugs such as ketamine, midazolam, tramadol, fentanyl, clonidine, dexmedetomidine have been used to prolong the duration of analgesia for the caudal block $[1,10]$. In our study, single shot caudal epidural using $1 \mathrm{ml} / \mathrm{kg}$ of $0.25 \%$ bupivacaine with $2 \mathrm{mg} / \mathrm{kg}$ tramadol or $2 \mu \mathrm{g} / \mathrm{kg}$ fentanyl with a maximum volume of $12 \mathrm{ml}$ were given.

Tramadol is a racemic mixture of two enantiomers. The (+) enantiomer has moderate affinity for the opioid $\mu$ receptor, which is greater than that of the $(-)$ enantiomer. In addition, the $(+)$ enantiomer inhibits serotonin reuptake, and the $(-)$ enantiomer is a norepinephrine reuptake inhibitor. These complementary properties result in a synergistic antinociceptive interaction between the two. The resulting opioid has a striking lack of respiratory depressant effect despite having analgesic potency approximately equal to that of pethidine [3]. Fentanyl is a synthetic opioid agonist. It exerts its analgesic action by binding to mu receptor, as well as to kappa and delta receptors within the spinal cord, producing spinal analgesia. It easily crosses the lumbar dura and penetrates quickly the lipid phase of the underlying tissue of the cord with minimal migration of opioids in rostral direction, hence, avoiding central nervous system depression of respiratory and cardiovascular system [11]. Caudal bupivacaine with tramadol $1 \mathrm{mg} / \mathrm{kg}$ provides prolonged, and good quality postoperative analgesia compared to plain bupivacaine in children [10-13].

Caudal tramadol $2 \mathrm{mg} / \mathrm{kg}$ with $0.5 \mathrm{mg} / \mathrm{kg}$ of $0.25 \%$ bupivacaine provided longer duration of postoperative analgesia up to 16 or $18 \mathrm{~h}$ without having significant side effects but with higher sedation score for $1 \mathrm{~h}$ postoperatively [4]. Similarly in our study, the duration of postoperative analgesia was more than $10 \mathrm{~h}$ up to $18 \mathrm{~h}$ without significant side effects in caudal bupivacaine $0.25 \% 1 \mathrm{ml} / \mathrm{kg}$ with tramadol $2 \mathrm{mg} / \mathrm{kg}$. Greater epidural use of tramadol $2 \mathrm{mg} / \mathrm{kg}$ may be preferred to morphine $0.1 \mathrm{mg} / \mathrm{kg}$ for postoperative analgesia in children undergoing urological surgery without any significant side effects [14]. Caudal tramadol 2mg/ $\mathrm{kg}$ combined with bupivacaine $0.25 \% 0.75 \mathrm{ml} / \mathrm{kg}$ provided longer duration of postoperative analgesia and reduced requirement for rescue analgesic compared with tramadol $1 \mathrm{mg} / \mathrm{kg}$ or $1.5 \mathrm{mg} / \mathrm{kg}$ in children undergoing inguinal herniotomy [15]. El Hamamsy et al. [3] observed analgesia for up to 4.5 and $5 \mathrm{~h}$ with caudal fentanyl $2 \mu \mathrm{g} / \mathrm{kg}$ and tramadol $2 \mathrm{mg} / \mathrm{kg}$, respectively. The mean duration of surgery was $140 \mathrm{~min}$. They also observed that if the period of time between performing the caudal injection and recovery of the child from anesthesia was $<2 \mathrm{~h}$, the incidence of immediate pain (requiring rescue analgesia) was high (30\%), demonstrating a slow onset of action of caudal tramadol.

However, with a longer duration surgery, caudal tramadol produced good quality analgesia for an average of $10.7 \mathrm{~h}$. The slow onset of action of caudal tramadol may imply that there is little advantage in injecting tramadol into the extradural space. Bupivacaine tramadol may prove more useful in young children and infants than other opioids because of its lack of respiratory depressant effects. A bupivacaine-fentanyl mixture as a single caudal epidural injection does not change the onset, quality and duration of analgesia and sedation score [3]. We observed analgesia for up to $11 \mathrm{~h}$ and $18 \mathrm{~h}$ with caudal fentanyl $2 \mu \mathrm{g} /$ $\mathrm{kg}$ and tramadol $2 \mathrm{mg} / \mathrm{kg}$, respectively. The time for onset of analgesia in both groups was respectively same. Prosser et al. [16] observed no significant effects of tramadol on prolongation of analgesic effects of bupivacaine when administered caudally after hypospadias surgery [16]. Cook and Doyle concluded that the addition of caudal fentanyl to local anesthetics offered no advantage over the administration of local anesthetics alone for short surgical procedures in children [17]. Doctor et al. [18] 
mentioned that addition of fentanyl $1 \mu \mathrm{g} / \mathrm{kg}$ to ropivacaine or bupivacaine administered through the caudal epidural route imparts no added advantage to bupivacaine except a less intense motor block in children undergoing surgery below the umbilicus. Kawaraguchi et al. [19] concluded that the addition of fentanyl $1 \mathrm{mg} / \mathrm{kg}$ to ropivacaine $0.2 \%$ for caudal analgesia provides no further analgesic advantages to ropivacaine.

Shukla et al. [5] observed a transient decrease of oxygen saturation to $91 \%$ in five cases and vomiting in eight patients out of 45 who received fentanyl $1 \mu \mathrm{g} / \mathrm{kg}$ with ropivacaine caudally. Patel mentioned in his case series that fentanyl does not prolong the duration of analgesia but significantly increases the incidence of nausea and vomiting [2]. El Hamamsy et al. [3] observed that caudal fentanyl $2 \mu \mathrm{g} / \mathrm{kg}$ produced useful analgesia for up to $4.5 \mathrm{~h}$. However, the addition of fentanyl to local anesthetics increased significantly the incidence of vomiting and desaturation compared with other groups who did not receive fentanyl. In our study, we observed that caudal fentanyl $2 \mu \mathrm{g} / \mathrm{kg}$ prolong the duration of analgesia with mild sedation in an immediate postoperative period without any side effects. Khalid mentioned postoperative analgesia up to $16 \pm 4 \mathrm{~h}$ with increased incidence of vomiting with tramadol 2mg/kg [12]. Demiraran et al. [14] reported statistically higher sedation scores in the morphine group compared with the tramadol group. The incidence of nausea and vomiting was $25 \%$ in the tramadol group.

Prakash et al. [15] concluded that the most frequently reported side effect of epidural tramadol is nausea. The longer time to first void in patients receiving tramadol $2 \mathrm{mg} / \mathrm{kg}$ though statistically significant appears clinically acceptable. None of the patients required bladder catheterization. In a study done by Prosser et al. [16], 35-40\% patient required a urinary catheter in bupivacaine and tramadol groups. According to them first indication for additional analgesia was related to the acute attack of bladder spasm [16]. In our study, nausea and vomiting were observed in four patients of Group BT, and respiratory depression and pruritus were not observed in any patients of both the groups. About 70-75\% patients in both groups were catheterized intraoperatively. Remaining patients did not have a problem to void urine postoperatively. The addition of caudal epidural analgesia to general anesthesia inhibits the stress responses from the lower part of the body during surgery and reduces the neurohormonal responses. It was demonstrated that small doses of a mixture of bupivacaine $0.25 \%$ alone or with fentanyl $1 \mu \mathrm{g} / \mathrm{kg}$ when administered through the caudal epidural does not have any beneficial effect on pain scores and catecholamine levels [20,21]. In our study intraoperatively, there was a decrease in the heart rate and systolic blood pressure and decreases the requirement of end tidal sevoflurane concentration in both the groups.

\section{Conclusion}

It can be concluded that the addition of Tramadol $2 \mathrm{mg} / \mathrm{kg}$ to Bupivacaine $0.125 \% 1 \mathrm{ml} / \mathrm{kg}$ resulted in prolonged duration of analgesia in comparison to Bupivacaine alone or with Fentanyl $1 \mathrm{mcg} / \mathrm{kg}$ in Caudal Block in the post operative period.

\section{References}

1. Acharya R, Jena SK, Samal S, Mishra SN (2013) Postoperative analgesia in pediatrics patients through caudal block with bupivacaine and two different doses of fentanyl-A comparative study. J Evol Med Dent Sci 2: 7568-7574.

2. Patel D (2006) Epidural analgesia for children. Contin Educ Anesth Crit Care Pain 6(2): 63-66.

3. Hamamsy EM, Elrahman AA, A Elaziz AEM, Zakaria D (2008) Prolongation of caudal analgesia in pediatric surgery: Comparison between dexmedetomidine, clonidine, tramadol, and fentanyl. Kasr EL Einy Med J 14: 1-10.

4. Samad R, Shah TH (2013) Comparison of caudal tramadol-bupivacaine and ketamine-bupivacaine for postoperative analgesia in children. J Surg Pak Int 18(2): 54-58.

5. Shukla U, Prabhakar T, Malhotra K (2011) Postoperative analgesia in children when using clonidine or fentanyl with ropivacaine given caudally. J Anesthesiol Clin Pharmacol 27(2): 205-210.

6. Nilsson S, Finnström B, Kokinsky E (2008) The FLACC behavioral scale for procedural pain assessment in children aged 5-16 years. Paediatr Anesth 18(8): 767-774.

7. Turan G, Yuksel G, Ormancý F (2012) Preemptive analgesia with paracetamol and tramadol in pediatric adenotonsillectomy. J Anesth Clin Res 3: 231.

8. Beyaz SG (2011) Comparison of postoperative analgesic efficacy of caudal block versus dorsal penile nerve block with levobupivacaine for circumcision in children. Korean J Pain 24(1): 31-35.

9. Ahmad S, Mohammad K, Ahmed M, Nazir I, Ommid M, et al. (2012) Caudal analgesia in pediatric patients: Comparison between bupivacaine and ropivacaine. Internet J Anesthesiol 30: 3.

10. Yasser M, Khairat M (2004) A comparison of caudally administered single dose bupivacaine and bupivacaine-tramadol combination for postoperative analgesia in children. JK Sci 6: 19-22.

11. Campbell FA, Yentis SM, Fear DW, Bissonnette B (1992) Analgesic efficacy and safety of a caudal bupivacaine-fentanyl mixture in children. Can J Anesth 39: 661-664.

12. Mehmood MT, Ahmed J, Haque SN (2009) Caudal bupivacaine tramadol low dose combination for post-operative analgesia in pediatric patients. Pak J Surg 25: 88-92.

13. Laiq N, Khan MN, Tahmeedullah, Gandapur YK, Khan S (2009) Comparison of caudal bupivacaine and bupivacaine-tramadol for postoperative analgesia in children undergoing hypospadias surgery. J Coll Physicians Surg Pak 19(11): 678-681.

14. Demiraran Y, Kocaman B, Akman RY (2005) A comparison of the postoperative analgesic efficacy of single-dose epidural tramadol versus morphine in children. Br J Anesth 95(4): 510-513.

15. Prakash S, Tyagi R, Gogia AR, Singh R, Prakash S (2006) Efficacy of three doses of tramadol with bupivacaine for caudal analgesia in paediatric inguinal herniotomy. Br J Anesth 97(3): 385-388.

16. Prosser DP, Davis A, Booker PD, Murray A (1997) Caudal tramadol for postoperative analgesia in pediatric hypospadias surgery. $\mathrm{Br} \mathrm{J}$ Anesth 79(3): 293-296.

17. Cook B, Doyle E (1996) The use of additives to local Anesthetic solutions for caudal epidural blockade. Paediatr Anesth 6(5): 353-359.

18. Doctor TP, Dalwadi DB, Abraham L, Shah N, Chadha IA, et al. (2013) 
Comparison of ropivacaine and bupivacaine with fentanyl for caudal epidural in pediatric surgery. Anesth Essays Res 7(2): 212-215.

19. Kawaraguchi Y, Otomo T, Ota C, Uchida N, Taniguchi A, et al. (2006) A prospective, double-blind, randomized trial of caudal block using ropivacaine $0.2 \%$ with or without fentanyl 1 microg kg- 1 in children. Br J Anesth 97(6): 858-861.
20. Koinig H, Krenn CG, Glaser C, Marhofer P, Wildling E, et al. (1999) The dose-response of caudal ropivacaine in children. Anesthesiology 90 1339-1344.

21. Gaitini LA, Somri M, Vaida SJ, Yanovski B, Mogilner G, et al. (2000) Does the addition of fentanyl to bupivacaine in caudal epidural block have an effect on the plasma level of catecholamines in children? Anesth Analg 90(5): 1029-1033.

Your next submission with Juniper Publishers will reach you the below assets

- Quality Editorial service

- Swift Peer Review

- Reprints availability

- E-prints Service

- Manuscript Podcast for convenient understanding

- Global attainment for your research

- Manuscript accessibility in different formats

( Pdf, E-pub, Full Text, Audio)

- Unceasing customer service

Track the below URL for one-step submission https://juniperpublishers.com/online-submission.php 